ISSN 0258-7122

Bangladesh J. Agril. Res. 40(2): 259-270, June 2015

\title{
IMPROVEMENT FROM MUSTARD-BORO-T. AMAN CROPPING PATTERN TO MUSTARD-BORO-JUTE-T. AMAN
}

\author{
M. M. RAHMAN ${ }^{1}$, M. A. RAHAMAN ${ }^{2}$, M. AHMED ${ }^{3}$ \\ M. M. UDDIN ${ }^{4}$, AND A. K. CHOUDHURY ${ }^{5}$
}

\begin{abstract}
The experiment was conducted at the farmers field of FSRD site, Elenga and MLT site Modhupur, Tangail during two consecutive years 2011-12 and 201213 to study the productivity, production efficiency, land use efficiency and economic return of the improved cropping pattern (Mustard - Boro - Jute - T Aman) against the existing cropping pattern (Mustard -Boro - T. Aman) through incorporating of modern crop varieties and improved management practices. The experiment was laid out in randomized complete block design with six dispersed replications. The pooled data of improved management practice for the pattern produced significantly higher yield in Mustard and T. Aman rice respectively and also gave additional jute yield. The gross return and gross margin were higher in improved pattern compared to that of existing farmer's pattern with only 149 and $151 \%$ extra cost at FSRD site, Elenga and MLT site Modhupur, respectively. The higher benefit cost ratio (1.74 and 1.79), rice equivalent yield (22.41 and 21.82), production efficiency (40.19 and 39.48) and land-use efficiency ( 95.75 and 96.48) indicated the superiority of the improved pattern over the farmer's existing pattern at both sites. Higher rice equivalent yield indicates that improved cropping pattern (Mustard - Boro - Jute -T. Aman) could be suitable in Tangail region for increasing crop productivity as well as cropping intensity.
\end{abstract}

Keywords: Improved cropping pattern, rice equivalent yield, land use efficiency and production efficiency.

\section{Introduction}

Bangladesh is predominately an agrarian country. Bangladesh has achieved a remarkable progress in increasing food production. Although, there has been a great success in rice production and about to self sufficient in food grain production, but increasing population in future when the natural resources, land and water are shrinking and degrading. Horizontal expansion is very limited, but increase in crop production could be possible with vertical expansion through increasing crop yield per unit area and by reducing production losses.

A cropping pattern is the yearly sequence, temporal and spatial arrangement of crops in a given land area. The cropping pattern and the changes therein depend

${ }^{1}$ Senior Scientific Officer, ${ }^{2 \& 3}$ Scientific Officer, ${ }^{4}$ Principal Scientific Officer, OFRD, Bangladesh Agricultural Research Institute (BARI), Tangail, ${ }^{5}$ Principal Scientific Officer, OFRD, BARI, Gazipur, Bangladesh. 
on a large number of factors like climate, soil type, rainfall, agricultural technology, availability of irrigation facilities and other inputs, marketing and transport facilities and growth of agro-industries (Neena, 1998; Gadge, 2003). The cropping pattern in an area depends largely on agro-climatic, technical and institutional factors (Vaidyanathan, 1987).

Rice is the staple food and the economy mainly depends on rice production in Bangladesh and now occupies the $4^{\text {th }}$ position in the world. In self sufficiency of rice, the dominant cropping pattern T. Aman (wet season rice)-Fallow-Boro (dry season rice) plays an important role which covers about 1.8 million hectare (about 22\% of the total land) of land (Elahi et al., 1999).

Bangladesh Rice Research Institute (BRRI) has recommended the T. AmanMustard-Boro cropping pattern for the irrigated ecosystem (BARC, 2001; Khan et al., 2004) with the inclusion of 70-75 days local mustard variety (Tori 7) in the transition period between T. Aman and Boro rice. But the farmers harvest poor yield from local var. Tori7 that can be increased manifold by introducing high yielding varieties (Alam and Rahman, 2006; Basak et al., 2007). Recently, Bangladesh Agricultural Research Institute (BARI) has developed high yielding yellow seeded mustard (Brassica campestris) varieties, BARI Sarisha-14 and BARI Sarisha-15 whose yield potential is higher than Tori-7 and have been recommended for T. Aman-Mustard-Boro cropping sequence (BARI, 2011). Inclusion of these new varieties of mustard with growth duration of 80-85 days in between existing medium duration T. Aman rice (135-140 days) and Boro rice can create opportunity to fit in the T. Aman -Fallow-Boro cropping sequence. Mustard-Boro-T. Aman is one of the existing dominant cropping pattern at FSRD site, Elenga and MLT site Modhupur, Tangail. The pattern covers around $16.25 \%$ of the cultivated land of the locality (DAE, 2012). Land remains fallow for more than 80 days after harvest of Boro rice. The present cropping intensity is $200 \%$. To boost up crop production, four-crops based cropping pattern need to be developed. Jute may be included after harvest of Boro rice. It is only possible, if jute is cultivated early and short duration T. Aman and Boro rice varieties are included in the pattern. Jute crops can be grown easily under moisture stressed condition in high to medium low land (BJRI, 1990). The crop residue from jute crop contributed to enrich soil fertility and benefit the succeeding rice crop (Singh and Ghosh, 1999).

Therefore, the present study was designed to evaluate the feasibility and profitability of four crops based cropping pattern in Tangail region.

\section{Materials and Method}

The improved cropping pattern with Mustard - Boro -Jute - T.Aman against the existing pattern Mustard-Boro- T.Aman was initiated under medium high land 
situation at the FSRD site, Elenga (AEZ 8) and MLT site Modhupur (AEZ 28), Tangail during 2011-12 and 2012-13. The trial was laid out in RCB design with six dispersed replications in both the locations. Unit plot size was $10 \mathrm{~m} \times 8 \mathrm{~m}$. All agronomic activities including sowing/ transplanting and harvesting dates, seed rate, plant spacing, fertilizer management etc. are shown in Tables 1a and 1b. Recommended fertilizer packages following the application methods were used for all the crops (BARC, 2005). Irrigation, pest managements and other intercultural operations were done as and when necessary. Land use efficiency, production efficiency, sustainable yield index and rice equivalent yield of cropping patterns were calculated by the following formulae:

\section{Land use efficiency}

Land use efficiency is worked out by taking total duration of individual crop in a sequence divided by 365 days (Tomer and Tiwari, 1990). It is calculated by following formula.

$$
\text { Land use efficiency }=\frac{\mathrm{d}_{1}+\mathrm{d}_{2}+\mathrm{d}_{3}+\mathrm{d}_{4}}{365} \times 100
$$

Where, $d_{1}, d_{2}, d_{3}$ and $d_{4}$, the duration of first, second, third and fourth crop of the pattern.

\section{Production efficiency}

Production efficiency values in terms of $\mathrm{Kg}$. $\mathrm{ha}^{-1} \mathrm{day}^{-1}$ were calculated by total production in a cropping sequence divided by total duration of crops in that sequence (Tomer and Tiwari. 1990).

$$
\text { Production efficiency }=\frac{Y_{1}+Y_{2}+Y_{3}+Y_{4}}{d_{1}+d_{2}+d_{3}+d_{4}}
$$

Where,

$\mathrm{Y}_{1}$ : Yield of $1^{\text {st }}$ crop

$\mathrm{Y}_{2}$ : Yield of $2^{\text {nd }}$ crop

$\mathrm{Y}_{3}$ : Yield of $3^{\text {rd }}$ crop

$\mathrm{Y}_{4}$ : Yield of $4^{\text {th }}$ crop

$\mathrm{d}_{1}=$ Duration of $1^{\text {st }}$ crop of the pattern

$\mathrm{d}_{2}=$ Duration of $2^{\text {nd }}$ crop of the pattern

$\mathrm{d}_{3}=$ Duration of $3^{\text {rd }}$ crop of the pattern

$\mathrm{d}_{4}=$ Duration of $4^{\text {th }}$ crop of the pattern 


\section{Rice Equivalent Yield (REY)}

For comparison between crop sequences, the yield of all crops was converted into rice equivalent on the basis of prevailing market price of individual crop (Verma and Modgal, 1983). The economic indices like gross, net returns and benefit cost ratio were also calculated on the basis of prevailing market price of the inputs and outputs (produces).

Crop management practices of improved and existing cropping pattern are shown in Table 1a and $1 \mathrm{~b}$. Crop productivity, LUE, production efficiency are also given in $2 \mathrm{a}, 2 \mathrm{~b}, 3 \mathrm{a}$ and $3 \mathrm{~b}$.

\section{Results and Discussion}

\section{Grain/Seed Yield}

The results showed in Table 2-3. Table $2 \mathrm{a}$ and $2 \mathrm{~b}$ reveal that Mustard-Boro-JuteT. Aman cropping pattern under improved practices (IP) gave higher grain yield in case of Mustard and T. Aman in all the years. On an average, the yield of Mustard and T. Aman in improved pattern increased by 88.32 and $51.34 \%$, respectively at the FSRD site, Elenga and 97.16 and $70.28 \%$, respectively at the MLT site, Modhupur, over the crops of the farmer's pattern because of using high yielding varieties and improved management practices. The yield of Boro rice in improved pattern decreased by $9.65 \%$ at the FSRD site, Elenga and $9.72 \%$ at the MLT site, Modhupur over the crops of the farmer's pattern but additional jute crop was introduced with fiber yield $2.59 \mathrm{t} \mathrm{ha}^{-1}$ without hampering the turn around time.

\section{Field duration}

Field duration of cropping pattern mainly depends on individual duration of component crops. In farmer's existing cropping pattern (FECP), (Mustard- BoroFallow-T. Aman) farmers used Tori-7 as mustard variety, BRRI dhan-29 in Boro and Pajam in Aman season. On the other hand in improved pattern BARI Sarisha14 was used as mustard variety, BRRI dhan-28 was used in Boro, O- 9897 as jute variety and Binadhan-7 in Aman season. BARI Sarisha-14 needs 4-5 more days to attained maturity than Tori-7 but BRRI dhan-28 matured 20-21 days earlier than BRRI Dhan-29 which helped in growing jute as an additional crop between Boro and T. Aman rice. Binadhan-7 took maturity 18 days earlier than Pajam. As a result, production efficiency and land use efficiency was higher in ICP than FECP. Though turn around time in improved pattern is very crucial so all inputs including land preparation should be done in proper time. 


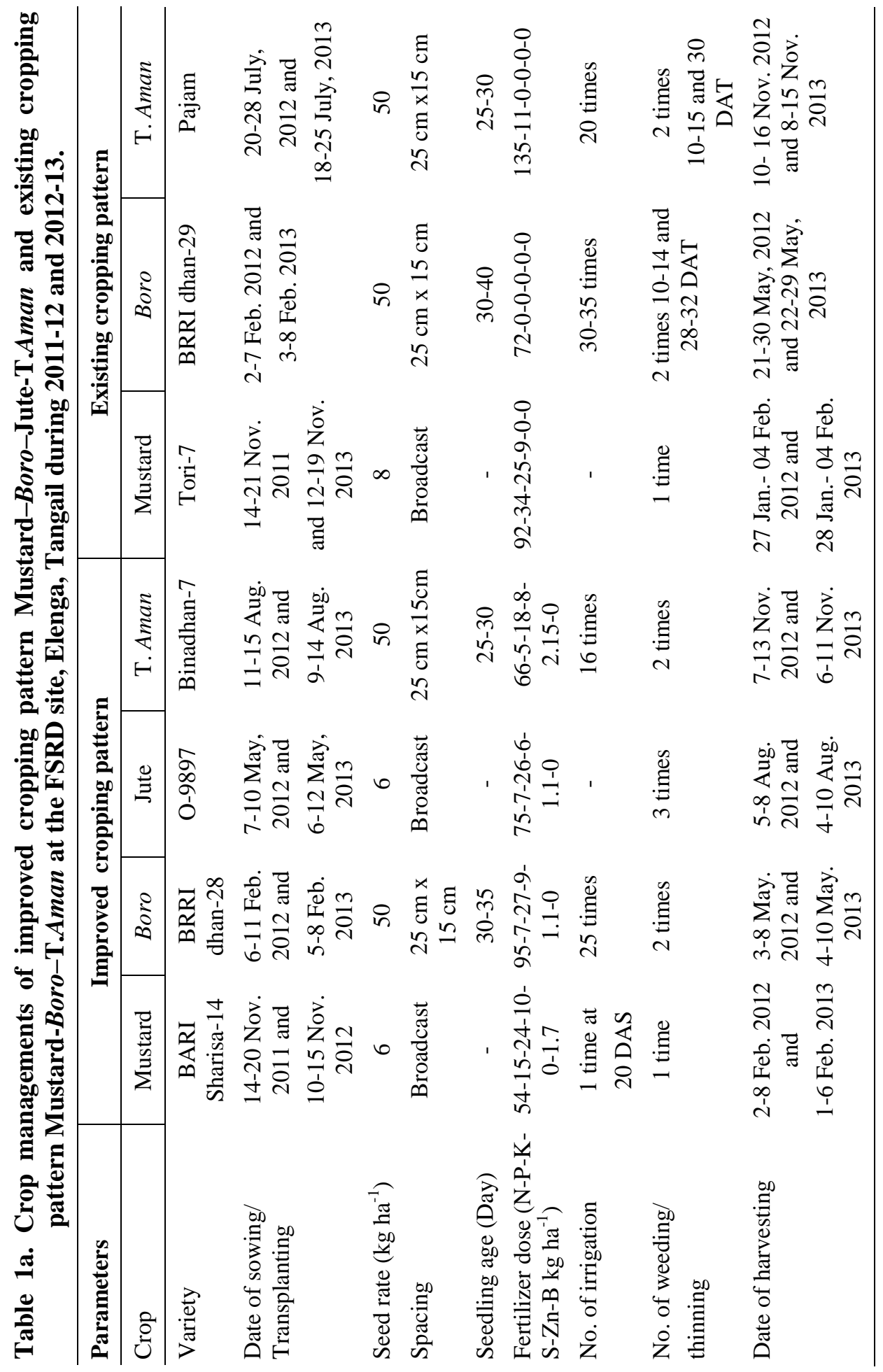




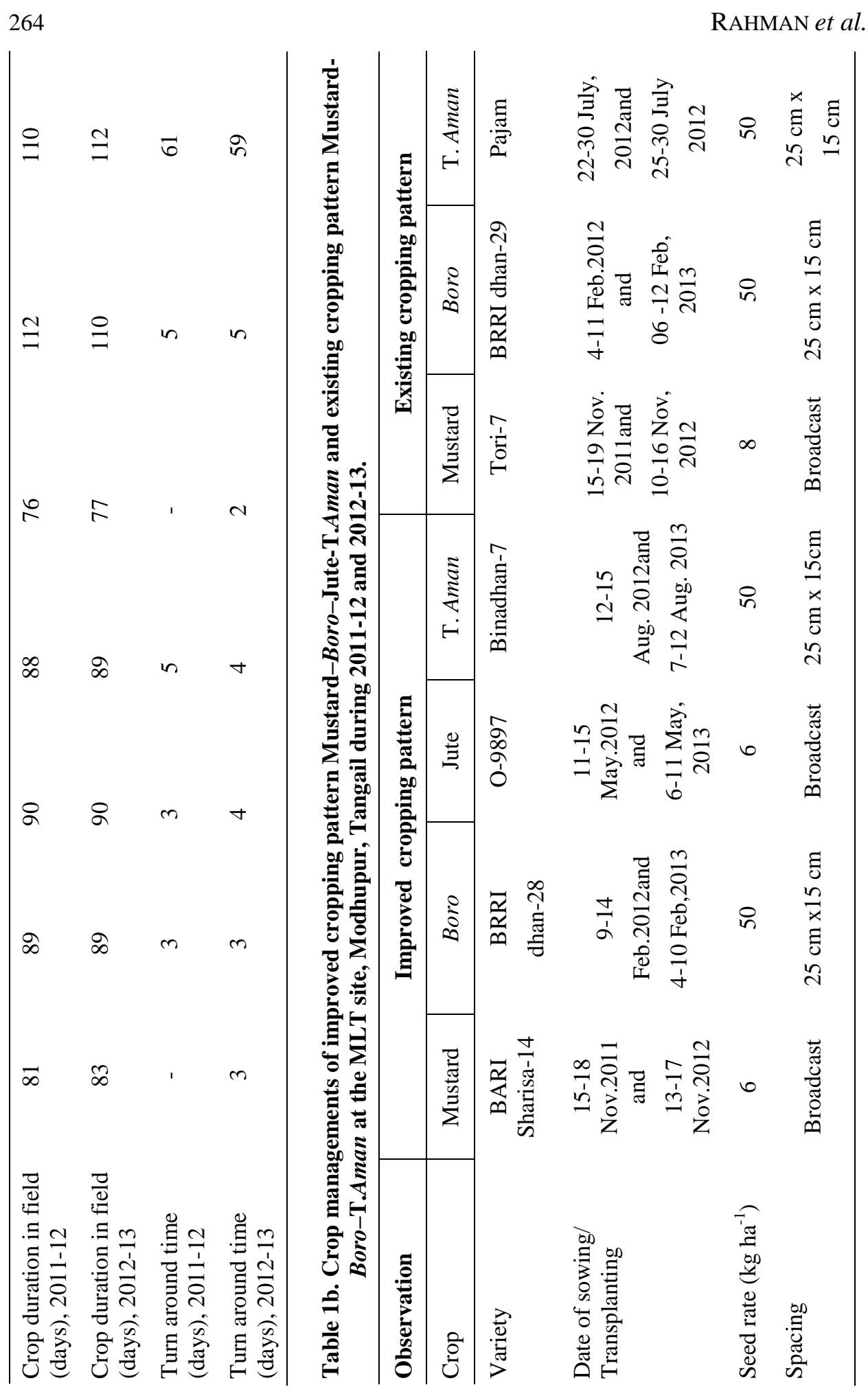




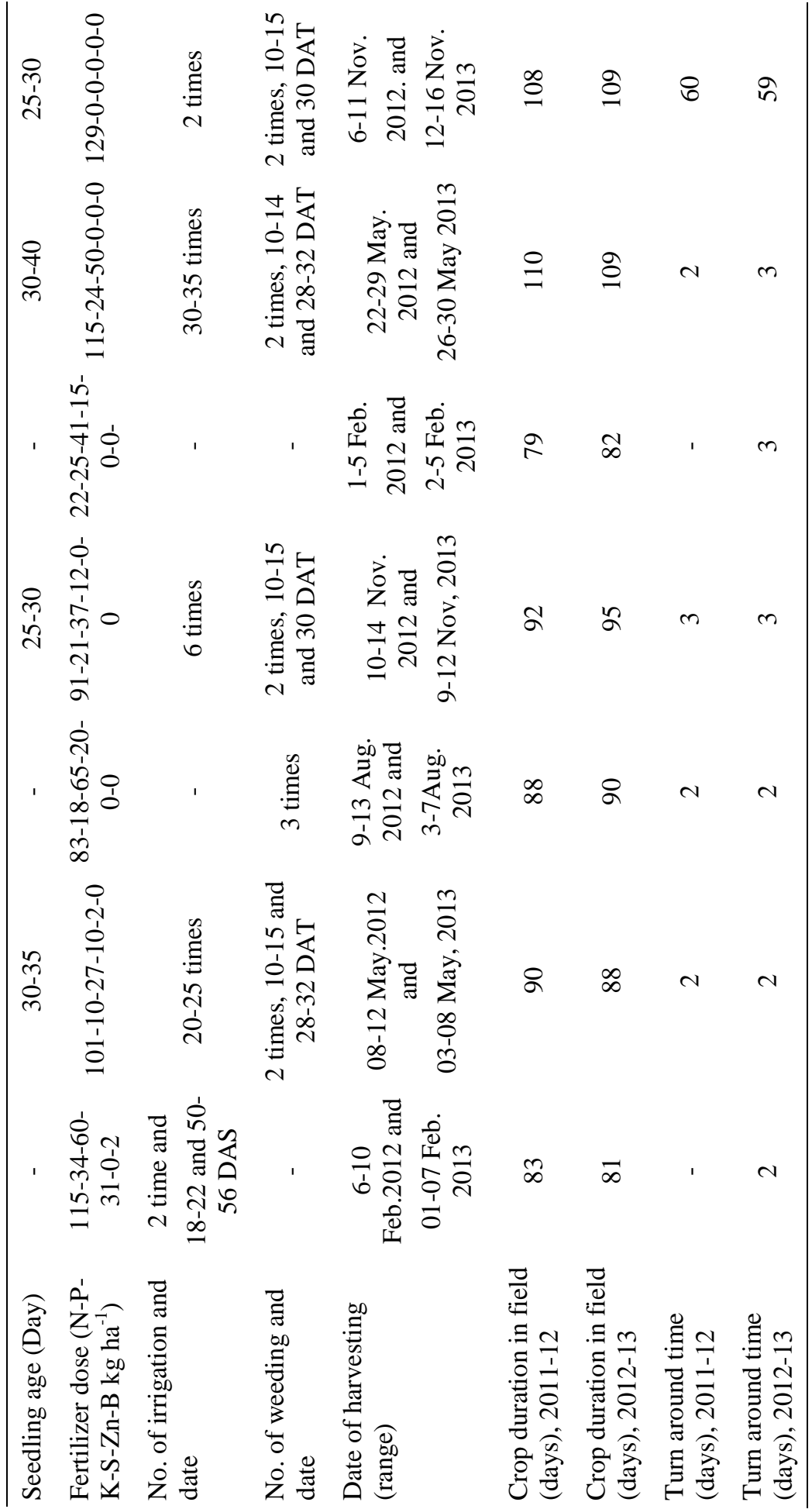




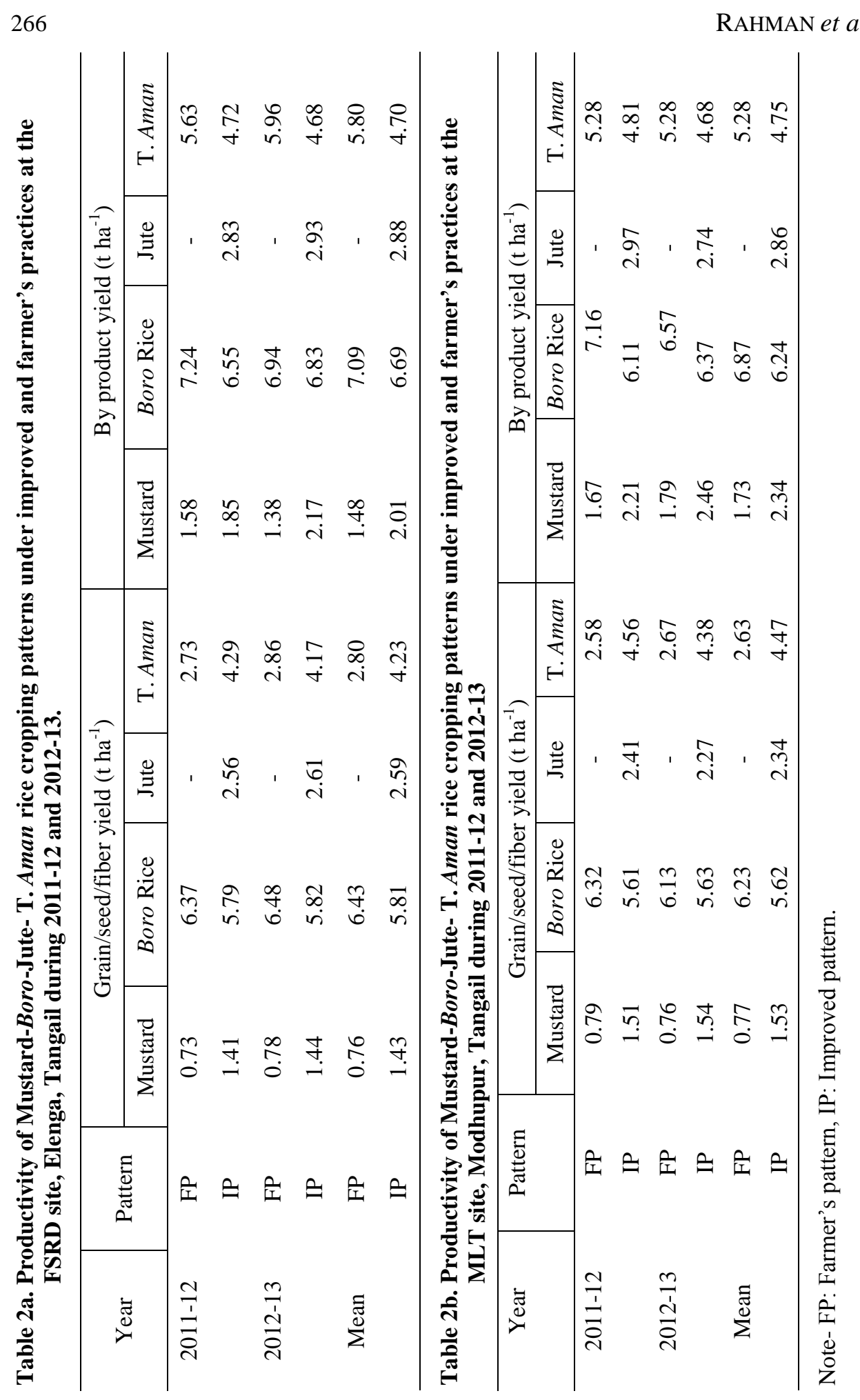




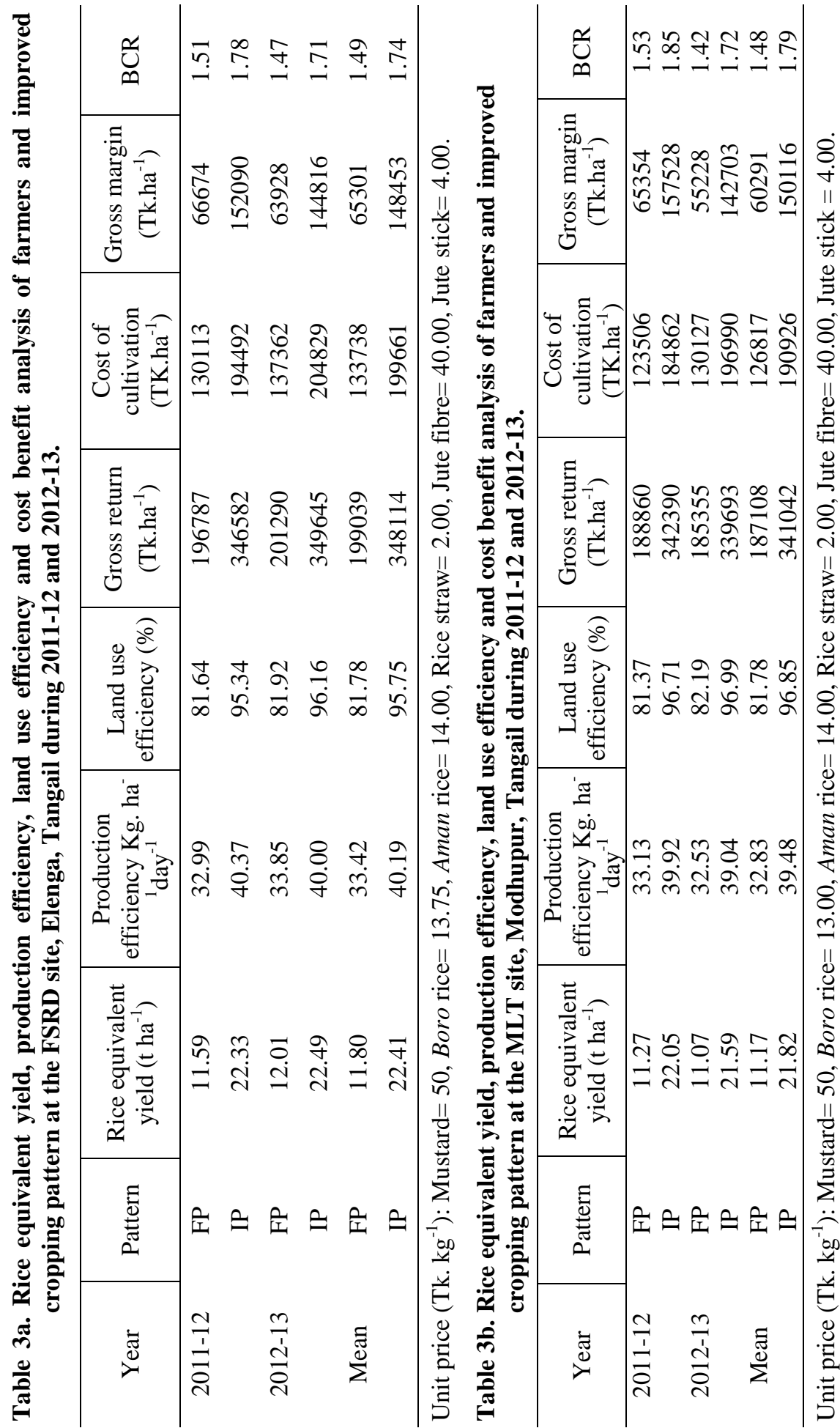




\section{Rice equivalent yield}

The mean rice equivalent yield revealed that improved cropping system produced higher rice equivalent yield over farmer's traditional cropping system (Tables 3a and $3 b$ ). Inclusion of a four crops with high yielding varieties and improvement management practices in the improved pattern increased the rice equivalent yield (22.41 and $\left.21.82 \mathrm{t} \mathrm{ha}^{-1}\right)$. The lower rice equivalent yield (11.80 and $\left.11.17 \mathrm{t} \mathrm{ha}^{-1}\right)$ was obtained in the farmer's pattern with three crops, local variety in mustard \& Aman rice and traditional management practices at the FSRD site, Elenga and MLT site Modhupur respectively.

\section{Production efficiency}

The lower production efficiency was observed in farmer's pattern (Tables 3a and $3 b)$. The result indicates that the crops remained in the field for shorter time and yields were also lower in farmer's traditional system, leading to lower production per day. On the contrary, crops remain standing in the field for longer time with higher yield in improved practices, leading to higher production efficiency.

\section{Land use efficiency}

Land use efficiency is the effective use of land in a cropping year, which mostly depends on crop duration. The average land-use efficiency indicated that improved pattern used the land for $95.75 \%$ period of the year at the FSRD site, Elenga and $96.85 \%$ at the MLT site Modhupur, whereas farmer's pattern used the land for $81.78 \%$ period of the year. This higher land use efficiency in improved pattern is due to cultivation of jute as a component crop in fallow period.

\section{Economic analysis}

From the economic point of view, the ICP (improved cropping pattern) showed its superiority over FECP (farmer's existing cropping pattern). Gross return of the ICP was Tk.348114, which was about $74.89 \%$ higher than that farmers pattern (Table 3a) at the FSRD site, Elenga. At the MLT site, Modhupur, gross return of the ICP was Tk.341042, which was about $82.27 \%$ higher than that of farmers pattern (Table $3 \mathrm{~b}$ ). The production cost per hectare of the improved pattern was higher than that of FECP. Higher cost for improved cropping pattern was due to cultivation of jute as a component crop, labor intensive, cultural operations, cost of fertilizer and other inputs. The gross margin was substantially higher in the improved pattern than that of the farmer's pattern. Though cost of cultivation in ICP was much higher but BCR was also higher due to higher benefit from the pattern. 


\section{Farmer's opinion}

The yield performances of the BARI Sharisha-14, BARI Sharisha-15, BRRI dhan-28, Falgunitusa (O-9897), Binadhan-7 and BRRI dhan-49 are found almost satisfactory performance. After harvest of T. Aman rice, short duration modern mustard variety (BARI Sharisha-14) could easily be grown which doesn't hamper or delay the Boro cultivation. Jute crop could easily be grown between Boro and T. Aman rice by using short duration Boro rice variety (BRRI dhan-28). Improved knowledge on production technology for four crops is needed.

\section{Conclusion}

Improved cropping pattern mustard (var. BARI Sarisha-14)-Boro (var. BRRI dhan-28)-Jute (var. O-9897)-T.Aman (var. Binadhan-7) is economically viable and biologically suitable technology. The findings may be used as extension message for large scale production but more training is required for the farmers before disseminated the technology.

\section{References}

Alam, M. M. and M. M. Rahman. 2006. Effect of row spacing on seed yield of five varieties of Rapeseed, Bangladesh J. Crop Sci. 17(1): Pp.163-168.

BARC (Bangladesh Agricultural Research Council). 2005. Fertilizer Recommendation Guide. Pp. 60-92.

BARC (Bangladesh Agricultural Research Council). 2001. A compendium: Packages of Technologies. A handbook for Farming Systems Development. M. F. Haque, M.A. Razzaque and Abu AkteruzzAman (editors). FSR and D program. Bangladesh Agril. Res. Council. P. 12.

Basak, N. C., J. C. Pandit, and M. H. Khurram. 2007. On-farm evaluation of three mustard varieties under different fertilizer packages. Bangladesh J. Sci. Ind. Res. 42(3): Pp. 335-340.

BJRI (Bangladesh Jute Research Institute). 1990. Pater Unnata Jatshomuha, A booklet in Bangla. Bangladesh Jute Research. Institute, Manik Mia, Avenew, Dhaka-1207.

DAE. 2012. Area and production of major crops and major cropping pattern of Tangail District. Department of Agricultural Extension (DAE), Tangail, Bangladesh. May 2012. P. 4.

Elahi, N. E., A. H. Khan, M. R. Siddique, A. Saha, M. Nasim, M. I. U Mollah, S. M. Shahidullah. 1999. Existing cropping patterns of Bangladesh, potential technologies and strategies for improving systems productivity. In proceedings of the workshop of modern rice cultivation in Bangladesh held during 14-16 February 1999. Pp 107-170.

Gadge, S. S. 2003. Influence of changes in cropping pattern on farmers' economic status. Indian J Ext Edu 39 (1 and 2): 99-101.

Khan. A. H., H. Rashid, A. Khatun, M. A. Quddus and A. R. Gomosta. 2004. Rice Farming System: improved rice-based cropping systems for different ecosystems. 
Paper presented at the National Farming Systems Technology Inventory Workshop held at CERDI, Gazipur-1701, July 17-19, 2004.

Neena, D. 1998. Interstate variation in cropping pattern in India. Indian J. Regi. Sci. 30(2), 57-69.

Singh, S. K. and B. C. Ghosh. 1999. Integrated nutrient management in jute (Corchorus capsularis) -rice (Oryza sativa) cropping system under rainfed lowlands. Idian J. Agric. Sci. 69(4): 300-301.

Tomer, S. S and A. S. Tiwari. 1990. Production potential and economics of different crop sequences. Indian J. of Agron. 35 (1, 2): 30-35.

Vaidyanathan, A. 1987. "Agricultural Development in Eastern India." Economic and Political Weekly, 22 (52), December 26.1987

Verma, S. P and S. C. Modgal. 1983. Production potential and economics of fertilizer application as resources constraints in maize, wheat crop sequence. Himachal $J$. Agric. Res. 9(2): 89-92. 